\title{
Funding Innovations for Sustainable Growth in Emerging Markets
}

\author{
Michael Neubert ${ }^{1}$ \\ ${ }^{1}$ ISM International School of Management, Paris, France \\ Correspondence: Michael Neubert, ISM International School of Management, 17, boulevard Raspail 75007 Paris, \\ France. Tel: 330-145-510-909. E-mail: michael.neubert@ faculty.ism.edu
}

Received: February 12, 2019

Accepted: February 28, 2019

Online Published: March 5, 2019

doi:10.5539/ijef.v11n4p16

URL: https://doi.org/10.5539/ijef.v11n4p16

\begin{abstract}
This study aims to understand the impact of fundraising innovations on sustainable growth in emerging markets. It opted for a multiple-case study research design using different sources of evidence, including nineteen semi-structured interviews. The subject matter experts (SMEs) were selected using a purposive selection method. The theoretical framework of Porter and Kramer is used. The results suggest that crowdinvesting, initial coin offerings, and accelerators might facilitate sustainable growth of private equity and venture capital markets in Africa due to entrepreneurial ecosystems and networks. The findings are relevant for founders and investors. The study contributes to the literature on entrepreneurial finance in emerging markets.
\end{abstract}

Keywords: venture capital, private equity, africa, initial coin offering, ico, cryptocurrencies, crowdfunding, accelerator, sustainability, entrepreneurship

\section{Introduction}

Policy makers, investors, and entrepreneurs from emerging markets need to gain a better understanding about the impact of fundraising innovations on sustainable growth in their home countries to facilitate entrepreneurship, growth, and employment (Drescher, 2017). Innovation is a key driver for sustainable growth (Porter \& Kramer, 2019) and private equity and venture capital (PEVC) has an impact on the growth of the funded firms (Memba, Gakure, \& Karanja, 2012). The PEVC industry and their ecosystems (e.g., Silicon Valley, Route 128) are facilitating successfully innovation and sustainable growth in developed markets (e.g., USA and Israel), but failed to show similar results if they were copied to other countries (e.g., emerging markets like Russia (Neubert, 1997)). The main reasons are inefficient regulatory, tax, and legal environments (Ahlers, Cumming, Günther, \& Schweizer, 2015) or the crowding-out of private investors due to government-supported PEVC (Afful-Dadzie \& Afful-Dadzie, 2016). Sustainable growth needs efficient PEVC ecosystems, the sustainability of entrepreneurs, and their ability to develop sustainable business models (Bocken, 2015).

This paper fulfils an identified need to study the impact of fundraising innovations on sustainable growth in emerging markets (Drover, Busenitz, Matusik, Townsend, Anglin, \& Dushnitsky, 2017). Its purpose is to identify the impact of fundraising innovations on sustainable growth of PEVC in emerging markets using the example of Africa. The paper's rationale is to close a gap in the literature and to better understand the benefits and impacts of fundraising innovations on sustainable growth in emerging markets, while proposing to model a theoretical framework outlining the impact of innovations and framework conditions on sustainable growth in emerging markets. It aims to expand the study of fundraising innovations on growth in emerging markets by including a deeper and broader range of innovative fundraising aspects and methods than is normally found in the private equity and venture capital literature.

A call for research by Drover et al. (2017) provided impetus for this study. In their paper, they call for further research about the field of fundraising innovations in the PEVC industry to close the gap in the literature about the impact of fundraising innovations on sustainable growth of the African PEVC industry. Therein, it is suggested that this need should be addressed through qualitative research methods, such as multiple case-study research to close this gap in the literature.

After an introduction, this paper offers a review of current and selected literature about fundraising innovations, the African PEVC market, and introduces the theoretical framework based on Porter and Kramer (2019). In the third chapter the research methods, the sample and the research questions are presented. The results of this multiple case study are presented in the fourth chapter to answer all five research questions individually, as well 
as offering a comparative analysis with other PEVC markets. The final chapter covers the conclusions and offers some implications for theory and practice as well as a brief agenda for future research.

\section{Literature Review}

The literature review is based on the purpose of the study. The theoretical framework is based on the notion that innovation is driving sustainable growth (Porter \& Kramer, 2019). Based on this theoretical framework, this study tries to gain a fundamental understanding, of whether technologically driven fundraising innovations might have an impact on sustainable growth of the African PEVC market.

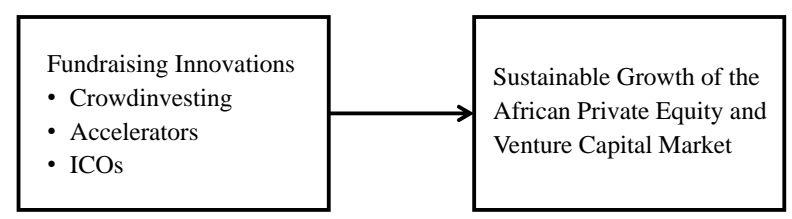

Figure 1. Theoretical concept

Source: author.

The main driver behind fundraising innovations is digitalization (Neubert, 2018). Digitalization leads to the development of new business models to disrupt traditional fundraising channels like family and friends, PEVC funds, grants, or bank loans. This literature review covers three examples of disruptive fundraising innovations based on digitalization.

\subsection{Fundraising Innovations}

\subsubsection{Equity Crowdfunding and Crowdinvesting}

This literature review focuses on equity-based crowdfunding, which needs to be differentiated from donation, reward, and lending-based crowdfunding (Wilson \& Testoni, 2014). Equity crowdfunding shares the same characteristic as all crowdfunding business models where a large number of investors contribute relatively small amounts of money to finance a project (Vulkan, Åstebro, \& Sierra, 2016). Equity crowdfunding is also called crowdinvesting, because investors receive the shares of a startup firm or of a convertible bond in return for their investment (Wilson \& Testoni, 2014). Equity crowdfunding is an innovative solution to give startups and founders better access to investors and investments (Fatoki, 2014).

The global transaction volume of crowdinvesting is expected to grow with a compound annual growth rate (CAGR) of 29.3\% from USD 11.2 billion (2018) to USD 31.3 billion (2022) (Statista, 2018). The average transaction volume is USD 164'515 (Statista, 2018). Hong Kong is expected to be the biggest global crowdinvesting market with a transaction volume of USD 3.2 billion in 2018 (Statista, 2018). A report of the crowdfunding platform Afrikstart (2016) demonstrates that there are over 50 crowdfunding platforms which raised USD 32.3 million with a regional focus on South Africa and Nigeria compared to a market potential of USD 2.5 billion estimated by the World Bank in 2013 (Drescher, 2017). These numbers represent far less than 1\% of the global crowdfunding market. Statista (2018) shows a crowdinvesting transaction volume of USD 186 million for South Africa. Even though these numbers differ significantly, they show that crowdinvesting and crowdfunding so far are not established in Africa (Drescher, 2017).

Many governments have realized the potential of crowdfunding and in particular of crowdinvesting for sustainable growth, because - besides bringing together entrepreneurs and investors - crowdinvesting platforms help to create ecosystems, to develop additional services, to train stakeholders, and to manage the investment (Moritz \& Block, 2016). Obviously, this requires an efficient regulation (Moritz \& Block, 2016; Ahlers et al., 2015) to benefit from the full potential of innovations like crowdinvesting. An excellent example is the Swiss crowdinvesting market (Salomon, 2016), where business angels and institutional investors invest efficiently seed and growth capital in promising high-tech firms to finance, for example, growth through internationalization (Neubert, 2017; 2018). According to Chirisa, Mukarwi and Matamanda (2018), there are numerous challenges for crowdinvesting in Africa. Crowdinvesting in Africa is still underdeveloped in comparison to other PEVC markets due to high levels of corruption, poverty, and poor governance in combination with a limited experience and expertise of investors and entrepreneurs (Berndt \& Mbassana, 2016; Neubert \& Van Der Krogt, 2017). This phenomenon can also be observed in other developing markets (Neubert \& Van Der Krogt, 2018). Crowdinvesting might be considered as an innovative and disruptive innovation, which might foster sustainable 
growth in Africa due to lower transaction cost, smaller and faster funding rounds, and lower minimal investments per investor and investment.

\subsubsection{Accelerators and Incubators}

Startup accelerators (including incubators) help startup firms during their early stages with financing, coaching, and training for a limited period of time (Hathaway, 2016). This term stands for all kind of organizations, which provide these kinds of services. (Pauwels, Clarysse, Wright, \& Van Hove, 2016). All participants in a cohort benefit from shared experiences in this startup ecosystem (Hathaway, 2016). Thus, startups participating in an accelerator program generally acquire clients (in new markets) and raise capital faster than startups, which didn't participate (Hallen, Bingham, \& Cohen, 2014). Their valuation is often higher, driven by tailor-made pricing models (Cohen \& Neubert, 2017; 2018) or tailor-made organizational structures and governance systems (AbdulJabbar \& Neubert, 2019). Startup accelerators also have a regional impact, because they help building up an ecosystem which attracts more investors, founders, and supporting services (Fehder \& Hochberg, 2015). According to Africa Startup Ecosystem (2018), the number of startup accelerators is constantly growing across in Africa, currently reaching 54 accelerators with different programs and cohorts.

\subsubsection{Cryptocurrencies and Initial Coin Offerings}

According to Amsden and Schweizer (2018), "Initial Coin Offerings (ICOs) are a new and unregulated form of crowdfunding that raises funds through a block chain by selling venture-related tokens or coins in exchange for legal tender or cryptocurrencies". Even though ICOs have existed since 2013, they have gained popularity with over USD 3 billion raised by more than 1000 organizations in 2016 and 2017 (Koverko \& Housser, 2018). Since February 2018, the financial market supervising authority of Switzerland (FINMA, 2018) offers a clear regulation and a stable framework for all investors and firms seeking to use ICOs for fundraising and investment purposes. There is currently no similar regulation in the most important African PEVC markets like Kenya, Nigeria, and South Africa, but they are expected to follow suit. Therefore, cryptocurrency firms from Africa like Bitpesa (bitpesa.co) or SureRemit (sureremit.co) have chosen other regulatory environments (e.g., UK, Mauritius, and Luxembourg) (Disrupt Africa, 2018). In these examples, ICOs and cryptocurrencies are a disruptive innovation for specific African applications (remittances). Further, ICOs and cryptocurrencies might offer an innovative fundraising alternative in markets with national currencies, which suffer from inflation, limited currency convertibility, and volatility. Due to unstable national currencies in many African PEVC markets, ICOs might be an alternative to satisfy (at least partially) the fundraising needs of start-up firms in facilitating sustainable growth.

\subsection{African Private Equity and Venture Capital Market}

According to the African Venture Capital Association (AVCA) (AVCA, 2018), 149 Private Equity (PE) deals were closed with a volume of USD 3.8 billion in 2017. Fundraising activities decreased to USD 2.3 billion in 2017 from USD 3.4 billion in 2016. South Africa and Nigeria show the highest PE activity. From 2012-2017, 32\% of all PE investments flew in the consumer industry, followed by the PE investments in financials (15\%) and industrials (14\%). Only $15 \%$ of all PE investments are invested in high-tech industries like information technology and health care. According to the AVCA (2018), the statistics are based on reported transactions. Thus, they cover the whole African PEVC market. The AVCA (located in London, UK) didn't answer any requests for additional, more specific data or clarification.

The global VCPE attractiveness index 2018 (Groh, Liechtenstein, Lieser, \& Biesinger, 2018) produces national and regional results based on criteria like economic activity, capital markets, taxation, investor protection, deal opportunities, or entrepreneurial culture and environment (Groh, Liechtenstein, \& Lieser, 2010). The 2018 regional index places Africa on the $8^{\text {th }}$ and last place with the lowest score in five of six criteria (Groh et al., 2018). Especially, the low score of the criteria "depth of the capital market" (Groh et al., 2018) demonstrates the need of the market potential in funding innovations.

The 2018 national index shows that South Africa is the most attractive African PEVC market (place 36 of 125), followed by Kenya (53), Morocco (64), Egypt (65), Tunisia (67), and Nigeria (72) (Groh et al., 2018). It also shows that since 2014, African countries were not able to improve their ranking positions significantly (Groh et al., 2018). A deeper analysis of the individual criteria confirms the results of the regional index. Even the most attractive African PEVC markets South Africa or Nigeria score low on important criteria like initial public offerings (IPOs), M \&A Market or Innovation (Groh et al., 2018). The literature review shows that there is a need to understand the impact of funding innovation on sustainable growth in African PEVC markets. 


\section{Research Methodology}

\subsection{Research Questions}

The purpose of the study and the gap in the literature has led to the following research questions:

1) What are the most important technological innovations of fundraising to foster sustainable growth of the African PEVC market?

2) How might technological innovations of fundraising foster sustainable growth of the African PEVC market?

3) Why might technological innovations of fundraising foster sustainable growth of the African PEVC market?

4) What are the main factors, which might influence the impact of technological innovations in fundraising on the sustainable growth of the African PEVC market?

5) Compare the impact of technological innovations in fundraising on the growth of the African PEVC market with other regions. Where do you see differences and similarities?

\subsection{Research Method}

The choice of the research method is based on the purpose of this exploratory study (Creswell \& Creswell, 2017), the gap in the literature and the research questions. A qualitative multiple case-study research method was used to contrast and compare SMEs' perceptions about the impact of fundraising innovations on PEVC activities in Africa (Yin, 2017). A multiple case-study research design was chosen, because it allows an in-depth analysis of complex research problems within a highly-contextualized environment, has more flexibility, and allows comparison across cases (Yin, 2017).

\subsection{Sampling Strategy}

The choice of the sampling strategy is based on the purpose of this study, which uses a purposive sampling strategy. Purposive sampling is a nonprobability sampling strategy used to select the most useful and appropriate SMEs to answer the research questions (Babbie, 2013). The sample consists of 19 SMEs in the field of Venture Capital and Private Equity. Seven SMEs (37\%) are from Africa, four from the US (21\%), three from the Middle East (15\%), three from Asia (15\%), and two from Europe (12\%). All SMEs have at least a master level as educational background, an expert knowledge, and a professional experience in the field of PEVC.

\subsection{Data Collection}

The interviews were conducted via an online questionnaire in Paris/France in April 2018 and took between 25-40 minutes. All SMEs answered all questions of the questionnaire. The response rate is $100 \%$. An online questionnaire with ten open-ended questions and an introduction was used to collect the SME's perceptions about the impact of fundraising innovations on sustainable growth of the African PEVC (Walliman, 2017) using mainly how, what, or why questions due to the explorative character of this study (Creswell \& Creswell, 2017). The questionnaire was tested in pilot study with two randomly selected SMEs (Babbie, 2013).

\subsection{Data Analysis}

Based on our research goal, the data analysis followed a logical sequence, starting with an individual analysis of the SME responses to each question followed by a qualitative cross-interview comparison to identify themes as well as differences and similarities between the answers (Walliman, 2017). Therefore, we coded the responses to the questions and remarks with a "label", which we attached to a word or a short sequence of words (example: "innovation"), created categories based on the codes (example: three categories fundraising innovations), and developed themes as a higher level of categorization (example: "Crowdinvesting reduces market entry barriers for investors and entrepreneurs"). Further, we tried to identify correlations between the different answers to support the arguments and to validate the SME answers.

\section{Findings}

\subsection{Answer to Research Question 1}

The findings of this multiple case study are presented to answer the first research question: What are the most important technological innovations of fundraising to foster sustainable growth of the African PEVC market?

According to the SMEs, crowdinvesting platforms, accelerators, and ICOs are the three most important technological innovations of fundraising to foster sustainable growth of the African PEVC market. In addition, most SMEs add that there are some preconditions, which need to be met before these three technological innovations of fundraising have an impact on sustainable growth. These preconditions are an efficient infrastructure including, for example, low cost or free access to smart phones and wireless broadband Internet, 
and internationally competitive regulatory and legal framework conditions.

The answer to research question 1 is that the most important technological innovations of fundraising to foster sustainable growth of the African PEVC market are crowdinvesting, accelerators, and ICOs, if the necessary preconditions are met.

\subsection{Answer to Research Question 2}

The findings of this multiple case study are presented to answer the second research question: How might technological innovations of fundraising foster sustainable growth of the African PEVC market?

The SMEs agree that disruptive innovations like crowdinvesting lead to sustainable growth, because of lower entry barriers for investors like business angels and entrepreneurs with their startup firms due to lower transaction and portfolio management cost. As a result, the minimum volume for funding rounds as well as the minimum investment per firm and round will decrease. This will give more entrepreneurs access to capital and more business angels the opportunity to invest. Finally, one SME adds that crowdinvesting platforms help in the creation of local ecosystems, which might lead to a higher quality and quantity of startups, higher valuations, and more investments.

During the discussion about accelerators, SMEs mainly focus on the coaching and training effect for the entrepreneur and the whole management team during the acceleration program. Further, SMEs expect similar network and ecosystem effects as with crowdinvesting platforms due to the exchange of experiences with other entrepreneurs, founders, and investors.

Most SMEs are still unsure how to evaluate the impact of ICOs on sustainable growth for the African PEVC market, because it is a rather new innovation of fundraising with very few experiences in emerging markets. Some SMEs discuss the possibility of African startups to use cryptocurrency platforms in Europe, Asia, or North America. This might give them access to capital and help them to overcome regulatory and currency constraints, to reduce transactions cost, to receive a better valuation, and to avoid dilution, and overly restrictive economic and control rights. Although, this sounds very appealing to most entrepreneurs, other SMEs don't see it as a realistic perspective for most African startups and doubt that it will lead to sustainable growth of the African PEVC market.

The answer to research question 2 is that technological disruptive innovations of fundraising might foster sustainable growth of the African PEVC market, because they lead to more and higher investments of more investors as well as more and better funded startup firms; if the right framework conditions exist.

\subsection{Answer to Research Question 3}

The findings of this multiple case study are presented to answer the third research question: Why might technological innovations of fundraising foster sustainable growth of the African PEVC market?

Most SMEs answer the third research question of why technological innovations of fundraising might foster sustainable growth of the African PEVC market, using the example of cryptocurrencies and, ICOs for fundraising. ICOs might foster sustainable growth, because they help to reduce political risk, missing regulation and infrastructure, if African investors and entrepreneurs use established ICO platforms like ethereum.org in Switzerland for funding purposes. One SME added that ICOs with new cryptocurrencies avoid traditional African problems with local currencies like high inflation or volatility, and restricted convertibility. Other SMEs mention that this also applies to international crowdfunding platforms like kickstarter.com, Y combinator, or even to the African crowdinvestment platform lelapafund.com, which uses French law. Further, African entrepreneurs might also participate in accelerator programs in higher developed markets and might benefit from the network effects of the eco-systems even if they are back to Africa.

One SME underlines the aspect of power between investors and entrepreneurs. In contrast to investment contracts of traditional Venture Capital funds (VC) (and also accelerators) with quite rigid economic and controlling rights, the power shifts to the side of entrepreneurs and offers them more flexibility, when using innovative sources of fundraising like ICOs or crowdinvesting. This is an important criterion for entrepreneurs to consider external sources of funding.

SMEs highlight the efficiency and speed (e.g., fundraising rounds require three to six months instead of 12 and relatively low costs for entrepreneurs), the ease (e.g., registration and preparation of documents), and the access to funding due to technological innovations. SMEs also mention secondary benefits of innovative funding platforms like increasing publicity, access to expert networks and human resources, or coaching (e.g., in accelerators). 
SMEs underline that the main reason, why technological innovations of fundraising might foster sustainable growth of the African PEVC markets, is that they offer a new and for many also the first possibility to raise respectively to invest capital due to lower entry barriers.

The answer to research question 3 is that technological innovations of fundraising might foster sustainable growth of the African PEVC market, because of a higher accessibility (lower entry barriers) for investors and entrepreneurs, a higher efficiency (faster and lower cost), and a significantly lower risk, if platforms and programs abroad are used.

\subsection{Answer to Research Question 4}

The findings of this multiple case study are presented to answer the fourth research question: What are the main factors, which might influence the impact of technological innovations in fundraising on sustainable growth of the African PEVC market?

The main factor to increase the impact of technological innovations in fundraising on sustainable growth of the African PEVC market is regulation. The majority of the SMEs confirm that "the absence of efficient regulation means an absence of adequate investor protection". The missing regulation about fundraising innovations like crowdfunding or ICOs, is a huge handicap for the African PEVC markets (Drescher, 2017).

The second factor is the lack of a reliable and fast IT infrastructure. According to the SMEs, this "will hinder" the ability of African PEVCs "to fully take advantage of the technological funding innovations", like crowdfunding or especially ICOs.

Besides the lack of infrastructure and regulation, SMEs mention additional impact factors like education, awareness (of politicians), and cultural differences in the sense that it is difficult to copy successful Venture Capital eco-systems and paste them in Africa.

The answer to research question 4 is that the main factors that influence the impact of technological innovations in fundraising on sustainable growth of the African PEVC market are regulation and infrastructure.

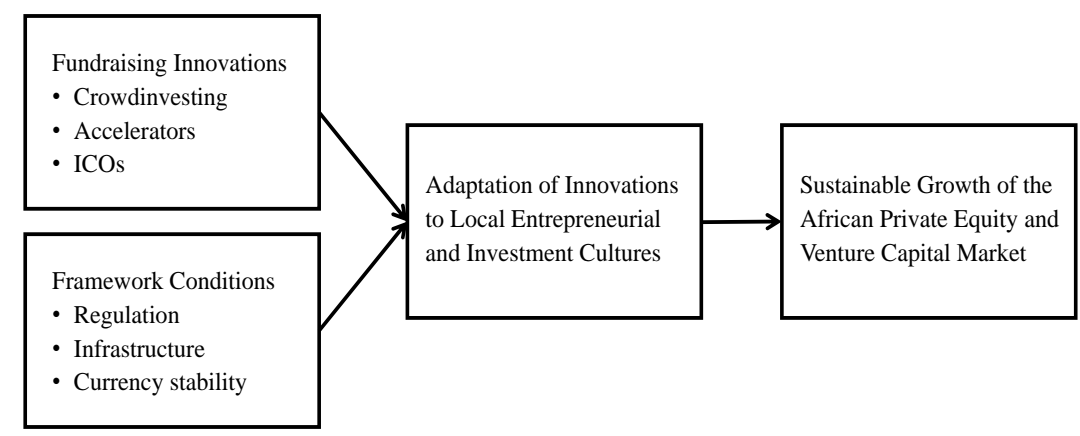

Figure 2. Innovations and framework conditions lead to sustainable growth

Source: author.

\subsection{Answer to Research Question 5}

The findings of this multiple case study are presented to answer the fifth research question: Compare the impact of technological innovations in fundraising on the growth of the African PEVC market with other regions. Where do you see differences and similarities?

One SME states that "there are mainly differences". In contrast to the North American, European (including Israel), or Asian PEVC, the African PEVC markets are still underdeveloped. Due to a less developed infrastructure, insufficient training and awareness, inefficient regulation, and - as another SME states - cultural differences, the adoption of funding innovations like crowdfunding, accelerators, or cryptocurrencies and ICOs require more time in African PEVC markets. One SME confirmed this statement with the fact that "computer processing power required for mining and transactions is still relatively expensive in Africa". Further, most SMEs state that other PEVC markets are more interesting for African and international investors and entrepreneurs, because of lower risk, highly developed eco-systems, or higher valuations and funding rounds. According to several SMEs, the development of ICOs is a perfect example for the challenges of the African PEVC markets. While they are still illegal and not regulated in Africa, higher developed PEVC markets like 
Switzerland compete actively for additional market shares. One SME mentioned a potential similarity, which African PEVC markets share with higher developed PEVC markets (except the US), is the difficult access to growth capital and exit markets with attractive valuations.

The answer to research question 5 is that the African PEVC markets are less developed, which leads to a slower adoption of funding innovations for sustainable economic growth. This means, that due to underdeveloped framework conditions and a missing adaption to the local culture, the African PEVC markets so far don't benefit from funding innovations as much as other PEVC markets, if you compare the potential (compare to figure 2).

\section{Conclusion}

This study offers additional, qualitative insights about the impact of fundraising innovations on sustainable growth in emerging markets, using the example of the African PEVC markets and theoretical framework of Porter and Kramer (2019). It is based on an identified gap in the literature and a call for research by Drover et al. (2017). This study has selected a qualitative multiple case-study research design as research method. The data are collected through 19 SME interviews as a primary source of evidence. Grounded theory is used to analyze the collected data.

The findings of this study confirm the results of Porter and Kramer (2019) that innovation drives sustainable growth. They suggest that fundraising innovations in African PEVC markets need the right framework conditions like a highly developed technical and efficient legal infrastructure, and need to be adapted to local market requirements of local entrepreneurs and investors to show their full impact on sustainable growth (see figure 2).

The most important technological innovations of fundraising to foster sustainable growth of the African PEVC market are crowdinvesting, accelerators, and ICOs. These fundraising innovations might foster sustainable growth, because they lead to more startups, more financing rounds, and higher investments per round by more investors. The main reasons for a positive impact on sustainable growth in the African PEVC markets are,

- a higher accessibility to lower market entry barriers for both investors and entrepreneurs/founders,

- a higher efficiency due to lower transaction and management cost as well as faster fundraising rounds, and

- a significantly lower risk due to highly standardized contracts and the possibility to create trustful personal relations with shared experiences and learning in the entrepreneurial networks and ecosystems.

The main impact factors of technological innovations in fundraising on sustainable growth of the African PEVC market are a highly developed technical infrastructure, an efficient regulatory, tax, and legal framework, and an adaption of these digital innovation to local market needs. If these framework conditions are not met, the adoption of fundraising innovations will require more time and won't show the expected impact.

The findings are relevant for scholars, researchers, entrepreneurs, investors, and policy makers who support activities that promote entrepreneurial activity in emerging markets, to better understand the impact of fundraising innovations on sustainable growth of the African PEVC industry, and to realize that the existence of the relevant framework conditions is a prerequisite for fundraising innovations to show their full potential.

While offering new ideas for future research, a multiple case-study research design has several limitations in scope and size. Future scholarly work should include more robust quantitative assessments of SMEs' perceptions with qualitative and quantitative data to provide greater clarification of the statistical significance of the study's variables, or replicate it with other global regions, and with funding innovations at different stages of development.

\section{References}

AbdulJabbar, R., \& Neubert, M. (2019). Valuation perspectives of family-owned real-estate companies in Saudi Arabia. International Journal of Teaching and Case Studies, 10(1), 72-86. https://doi.org/10.1504/IJTCS.2019.096875

Afful-Dadzie, E., \& Afful-Dadzie, A. (2016). A decision-making model for selecting start-up businesses in a government venture capital scheme. Management Decision, 54(3), 714-734. https://doi.org/10.1108/MD-06-2015-0226

Africa Startup Ecosystem. (2018). List of accelerator programs in Africa. Retrieved from http://africastartupecosystem.com/resources/accelerators/
Afrikstart.
(2016).
Crowdfunding
in Africa.
Retrieved
from http://afrikstart.com/report/wp-content/uploads/2016/09/Afrikstart-Crowdfunding-In-Africa-Report.pdf 
Ahlers, G. K., Cumming, D., Günther, C., \& Schweizer, D. (2015). Signaling in equity crowdfunding. Entrepreneurship Theory and Practice, 39(4), 955-980. https://doi.org/10.1111/etap.12157

Amsden, R., \& Schweizer, D. (2018). Are Blockchain Crowdsales the New 'Gold Rush'? Success determinants of initial coin offerings (April 16, 2018). http://dx.doi.org/10.2139/ssrn.3163849

AVCA. (2018). 2017 Annual African private equity data tracker and regional spotlights. Retrieved from https://www.avca-africa.org/research-publications/data-reports/2017-annual-african-private-equity-data-trac ker-and-regional-spotlights/

Babbie, E. R. (2013). The basics of social research. Cengage learning.

Berndt, A., \& Mbassana, M. (2016). Crowdfunding: The beliefs of Rwandan entrepreneurs. Retrieved from http://urn.kb.se/resolve?

Bocken, N. M. P. (2015). Sustainable venture-capital catalyst for sustainable start-up success? Journal of Cleaner Production, 108, 647-658. https://doi.org/10.1016/j.jclepro.2015.05.079

Chirisa, I., Mukarwi, L., \& Matamanda, A. R. (2018). Prospects and options for sustainable and inclusive crowdfunding in African cities. In Crowdfunding and Sustainable Urban Development in Emerging Economies (pp. 211-231). IGI Global. https://doi.org/10.4018/978-1-5225-3952-0.ch011

Cohen, B., \& Neubert, M. (2017). Price-setting strategies for product innovations in the medtech industry. In $10^{\text {th }}$ Annual Conference of the EuroMed Academy of Business (pp. 457-473).

Cohen, B., \& Neubert, M. (2018). Corporate Valuation of SaaS Companies - A Case Study of Salesforce.com. In $11^{\text {th }}$ Annual Conference of the EuroMed Academy of Business (pp. 357-371).

Creswell, J. W., \& Creswell, J. D. (2017). Research design: Qualitative, quantitative, and mixed methods approaches. Sage publications.

Disrupt Africa. (2018). Why DraperDarkFlow is wary of ICOs in Africa. Retrieved from http://disrupt-africa.com/2018/02/why-draperdarkflow-is-wary-of-icos-in-africa/

Drescher, R. (2017). Supporting SMEs in Africa. In Development and Cooperation, Sep. 2017, pp. 18-19.

Drover, W., Busenitz, L., Matusik, S., Townsend, D., Anglin, A., \& Dushnitsky, G. (2017). A review and road map of entrepreneurial equity-financing research: Venture capital, corporate venture capital, angel investment, crowdfunding, and accelerators. Journal of Management, 43(6), 1820-1853. https://doi.org/10.1177/0149206317690584

Fatoki, O. (2014). The financing options for new small and medium enterprises in South Africa. Mediterranean Journal of Social Sciences, 5(20), 748. https://doi.org/10.5901/mjss.2014.v5n20p748

Fehder, D., \& Hochberg, Y. (2014). Accelerators and the regional supply of venture capital investment. http://dx.doi.org/10.2139/ssrn.2518668

FINMA. (2018). FINMA publishes ICO guidelines. Retrieved from https://www.finma.ch/en/news/2018/02/20180216-mm-ico-wegleitung/

Groh, A., Liechtenstein, H., \& Lieser, K. (2010). The european venture capital and private equity country attractiveness indices. Journal of Corporate Finance, 16(2), 205-224. https://doi.org/10.1016/j.jcorpfin.2009.09.003

Groh, A., Liechtenstein, H., Lieser, K., \& Biesinger, M. (2018). The venture capital and private equity country attractiveness index 2018. Retrieved from https://blog.iese.edu/vcpeindex/

Hallen, B. L., Bingham, C. B., \& Cohen, S. (2014). Do accelerators accelerate? A study of venture accelerators as a path to success? In Academy of management proceedings (Vol. 2014, No. 1, p. 12955). Briarcliff Manor, NY 10510: Academy of Management. https://doi.org/10.5465/ambpp.2014.185

Hathaway, I. (2016). What startup accelerators really do. Harvard Business Review. Retrieved from https://hbr.org/2016/03/what-startup-accelerators-really-do

Нойберт, М. (1997). Венчурный капитал и региональное экономическое развитие (на материалах США). Экономика России и мировой опыт, 6(3), 17-28.

Koverko, T., \& Housser, C. (2018). February 2018. growth, 4, 5. Retrieved from http://media.abnnewswire.net/media/en/whitepaper/rpt/94196-Polymath_White_Paper.pdf

Memba, S. F., Gakure, W. R., \& Karanja, K. (2012). Venture capital (VC): Its impact on growth of small and 
medium enterprises in Kenya. International Journal of Business and Social Science, 3(6), 32-38.

Moritz, A., \& Block, J. (2016). Crowdfunding: A literature review and research directions. In Crowdfunding in Europe (pp. 25-53). Springer, Cham. https://doi.org/10.1007/978-3-319-18017-5_3

Neubert, M. (1998). Computer aided selling: Informations-und Kommunikationssysteme zur Vertriebssteuerung von Versicherungsunternehmen. MMG Marketing \& Medien.

Neubert, M. (2017). International pricing strategies for born-global firms. Central European Business Review, 6(3), 41-50. https://doi.org/10.18267/j.cebr.185

Neubert, M. (2017). Lean internationalization: How to globalize early and fast in a small economy. Technology Innovation Management Review, 7(5), 16-22. https://doi.org/10.22215/timreview/1073

Neubert, M. (2018). Internationalisation behaviour of small and medium-sized enterprises from emerging markets: Implications for sustainability. Latin American Journal of Management for Sustainable Development, 4(3), 226-238. https://doi.org/10.1504/LAJMSD.2018.096072

Neubert, M. (2018). The impact of digitalization on the speed of internationalization of Lean Global Startups. Technology Innovation Management Review, 8(5), 44-54. http://doi.org/10.22215/timreview/1158

Neubert, M., \& Van Der Krogt, A. (2017). Lean internationalization of high-tech firms. Int. J. Teaching and Case Studies, 8(2/3), 133-150. https://doi.org/10.1504/IJTCS.2017.086679

Neubert, M., \& Van der Krogt, A. (2018). Impact of Business Intelligence Solutions on Export Performance of Software Firms in Emerging Economies. Technology Innovation Management Review, 8(9), 39-49. http://doi.org/10.22215/timreview/1185

Pauwels, C., Clarysse, B., Wright, M., \& Van Hove, J. (2016). Understanding a new generation incubation model: The accelerator. Technovation, 50, 13-24. https://doi.org/10.1016/j.technovation.2015.09.003

Porter, M. E., \& Kramer, M. R. (2019). Creating shared value. In Managing Sustainable Business (pp. 327-350). Springer, Dordrecht. https://doi.org/10.1007/978-94-024-1144-7_16

Salomon, V. (2016). Emergent models of financial intermediation for innovative companies: From venture capital to crowdinvesting platforms in Switzerland. Venture Capital, 18(1), 21-41. https://doi.org/10.1080/13691066.2015.1079953

Statista. (2018). Crowdinvesting, worldwide. $\quad$ Retrieved https://www.statista.com/outlook/377/100/crowdinvesting/worldwide\#

Vulkan, N., Åstebro, T., \& Sierra, M. F. (2016). Equity crowdfunding: A new phenomena. Journal of Business Venturing Insights, 5, 37-49. https://doi.org/10.1016/j.jbvi.2016.02.001

Walliman, N. (2017). Research methods: The basics. Routledge.

Wilson, K., \& Testoni, M. (2014). Improving the role of equity crowdfunding in Europe's capital markets. http://dx.doi.org/10.2139/ssrn.2502280

Yin, R. (2017). Case study research: Design and methods (6th ed.). Thousand Oaks, CA: Sage, Inc.

\section{Copyrights}

Copyright for this article is retained by the author(s), with first publication rights granted to the journal.

This is an open-access article distributed under the terms and conditions of the Creative Commons Attribution license (http://creativecommons.org/licenses/by/4.0/). 